\title{
La teología desde las publicaciones académicas en Colombia: un breve estado del arte
}

Andrés C. Rodríguez V.

Universidad Nacional

\section{Fecha: 2 de diciembre de 2019}

\section{Resumen}

Este artículo aborda algunas de las tendencias en la publicación sobre la disciplina y el conocimiento teológica, en el contexto del desarrollo histórico de Colombia. Es así que se observan tendencias de diversa índole, que abordan desde los estudios de teología dogmática, eclesiología, dialogó ecuménico, entre otros. Es importante mencionar, los estudios realizados sobre la teología de la liberación, y la influencia del Concilio Vaticano II y la Conferencia de Medellín.

Palabras clave: Teología, publicaciones, publicaciones académicas.

\section{Introducción}

Las ciencias humanas, específicamente la teología, han tenido una serie de renovaciones en la segunda mitad del siglo XX, y más aún en las primeras décadas del siglo XXI. La acción y el pensamiento del hombre en el tiempo, desde el plano terrenal y divino, encabezaron las apuestas y las preguntas como elementos de su qué hacer disciplinar. La indagación por el origen y desarrollo de la vida, se asoció con figuras divinas, lo que conllevó a la instauración de formas y modos de pensar que estudiaban el relacionamiento entre Dios, su sentido, desarrollo y atributo. ${ }^{1}$ El cristianismo, una religión monoteísta, cimentada en las obras y

\footnotetext{
1 José Luis Illanes y Josep-Ignasi Saranyana, Historia de la Teología, Biblioteca de Autores Cristianos 2002.
} 
enseñanzas de Jesús, nacido aproximadamente en el siglo I d.C. marcó un paradigma para Occidente. Los textos bíblicos, pero más específicamente los evangelios, lo mostraron como fuente de salvación que se edificaba sobre el amor al prójimo, la justicia para el oprimido y el aliciente para los pobres. ${ }^{2}$ La teología cristiana, cobró relevancia en la Edad Media, donde algunos de los llamados "doctores de la Iglesia", desplegaron sus capacidades conceptuales y analíticas para justificar el proyecto divino con base en las escrituras bíblicas a partir de la creencia como fuente de sentido. Así, aparecieron las disertaciones de San Agustín y Santo Tomás, entre otros, que sin duda incorporaron en sus disertaciones aspectos que hasta el día de hoy se conservan. El siglo XVI marcó una transformación en los modelos políticos, económicos y sociales, y frente a ello, el luteranismo apareció como alternativa a la corriente católica, situación que incluyó las disertaciones sobre Dios. Fue así que la teología católica, comienzó un proceso de reflexión que se asumió como la doctrina verdadera, en contraposición a la "falsa doctrina" que estaba ligada al paganismo. Grosso modo, la pregunta por Dios, se plantea desde la Revelación, a partir del misterio trinitario, y se diversifica en la soteriología (doctrina de la salvación centrado en la persona de Jesucristo), la mariología ${ }^{3}$ (dogmas y doctrinas marianas), la escatología ${ }^{4}$ (se preocupa por las "realidades últimas"), la ética teológica, la apologética $^{5}$ (defensa de la fe), entre otros. Sin embargo, la Teología dogmática, como rama especial, a partir de algunos concilios, formuló un andamiaje teórico organizado, que emanaba de la autoridad de la Iglesia

\footnotetext{
${ }^{2}$ Kreti Soledad Sanhueza Vidal, "Jesucristo, prototipo de justicia y martirio, a favor de los pobres y marginados", Cuestiones Teológicas Vol. 43, No. 99 (2016): 175-197. http://dx.doi.org/10.18566/cueteo.v43n99.a08

${ }^{3}$ Terrence J. McNally, What Every Catholic Should Know about Mary (Xlibris Corporation, 2009)

${ }^{4}$ José Antonio Sayés, Escatología (Madrid: Ediciones Palabrea, 2006).

${ }^{5}$ Avery Dulles, A History of Apologetics (Ignatius Press, 2005).
} 
y que también implicaba una relación con los laicos. ${ }^{6}$ En este contexto, este artículo analiza la producción en el ámbito de la teología, que se ha publicado en las revistas académicas de Colombia, dividiendo las secciones en algunas de las vertientes anteriormente mencionadas, y teniendo como temporalidad los últimos 10 años de producción académica. Así se pretende demostrar que la teología como disciplina está actualmente movilizando a una comunidad académica en construcción. ${ }^{7}$

\section{La teología en la historia del siglo XX colombiano}

Según el historiador británico Eric Hosbawn, el incio del siglo XX fue marcado por la Primera Guerra Mundial. La sociedad occidental se fracturó alrededor de disputas en el orden mundial en la política, la economía y la ideología. Muchos de los pensadores, acudieron incluso a pensar en una decadencia de Occidente, que sin duda tuvo un reflejo en Colombia. La Hegemonía Conservadora, propuso un Estado nacional centralizado, pero con una enorme prerrogativa a la Iglesia católica. El Concordato firmado entre ambos, condicionaba la vida social y familiar del país. Sin embargo, con la llegada de la República Liberal, en 1930, algunos de estos postulados chocaron con las nuevas realidades. Esta situación ha sido estudiada por las humanidades desde diferentes perspectivas, que de una u otra manera, reflejan posiciones que esgrimen el carácter modernizador

\footnotetext{
${ }^{6}$ Alberto Ramirez, "Fundamentos doctrinales para una teología sobre la acción del laico", Cuestiones Teológicas Vol. 10, Núm 26 (1983).

7 Un estudio aproximativo: Iván Darío Toro Jaramillo, “La bibliometría y las publicaciones en Teología”, Cuestiones Teológicas Vol. 44 No.102 (2018): 229-239.
} 
y reformados del Estado, frente a otras que lo señalan como medidas anticatólicas asociadas con la masonería, el comunismo y el protestantismo. ${ }^{8}$

Más adelante, la segunda mitad del siglo XX trajo reformas a las perspectivas teológicas y dogmáticas, que se ven igualmente reflejadas en los estudios sobre ellos. Uno de los movimientos más significativos en Latinoamérica, y especialmente en Colombia fue la Teología de la Liberación. Esta corriente tomó fuerza desde algunas conferencias o reuniones, tales como las Comunidades Eclesiales de Base, el Concilio Vaticano II y la Conferencia de Medellín (Colombia, 1968). ${ }^{9}$

Este movimiento, contextualmente asociado al socialismo o al marxismo, se enfocó en la reivindicación de las comunidades pobres y marginadas de las ciudades y campos latinoamericanos. Muchos de los sacerdotes encargados de parroquias locales, entablaron procesos de construcción barrial, que son reconocidos incluso en la actualidad. ${ }^{10}$ Es de anotar que

\footnotetext{
${ }^{8}$ Daniel Turriago Rojas, "La actitud de la Iglesia Católica colombiana durante las hegemonías liberal y conservadora de 1930 a 1953", Cuestiones Teológicas Vol. 44, No. 101 (2017): 67-94.

${ }^{9}$ Sobre ello abundan las investigaciones, ver especialmente: Gutiérrez, Gustavo, y Lucas F. Mateo Seco. Teología de la liberación (Lima: CEP, 1971). Phillip Berryman, Teología de la liberación: los hechos esenciales en torno al movimiento revolucionario en América Latina y otros lugares (Siglo XXI, 1989). Enrique Dussel, Teología de la Liberación: Un panorama de su desarrollo (Potrerrillo, 1995). Jairo Gómez Díaz, Adriana Alejandra Hoyos Camacho, Rosana Elena Navarro Sánchez, et al., "El sentido teológico de una espiritualidad en camino la espiritualidad de la liberación entre Puebla y Santo Domingo", Cuestiones Teológicas Vol. 43, No. 99 (2016): 149-174. Victorino Pérez Prieto, "Los orígenes de la teología de la liberación en Colombia Richard Shaull, Camilo Torres, Rafael Ávila, "Golconda", sacerdotes para América Latina, cristianos por el socialismo y comunidades eclesiales de base", Cuestiones Teológicas Vol. 43, No. 99 (2016): 73-108. Julio Lois, Teología de la liberación: opción por los pobres. Vol. 1. (IEPALA Editorial, 1986). Christopher Rowland, ed, La teología de la liberación. Vol. 7. (Ediciones AKAL, 2000). Malik Tahar Chaouch, "La teología de la liberación en América Latina: una relectura sociológica." Revista mexicana de sociología 69.3 (2007): 427-456. Jon Sobrino, "La centralidad del "reino de Dios" en la teología de la liberación." Revista latinoamericana de teología vol. 3, no. 9, p. 247281. (1986). Ignacio Ellacuría, "La teología de la liberación frente al cambio sociohistórico de América Latina." Revista latinoamericana de teología vol. 4, no. 12, p. 241-263. (1987).

${ }^{10}$ Alberto Ramírez, "La teología del laicado desde el Concilio Vaticano II hasta el sínodo mundial actual" Cuestiones Teológicas Vol. 14 No.39 (2019): 47-64.
} 
ello trajo, a su vez, una renovación en los estudios sobre el sacerdocio ${ }^{11}$ y el papel de la eucaristía.

\section{Los estudios durante el nuevo siglo}

Es evidente en la litera más reciente, un interés por los estudios que inculan la teología con el mundo actual, sus dinámicas y trasformaciones, que afectan las nociones tradicionales, la praxis e incentivan los estudios del diálogo ecuménico entre la religión católica y algunas otras iglesias de corriente protestante. ${ }^{12}$ Asimismo, se evidencia un interés por estudiar los efectos del movimiento posmoderno en la Iglesia y su relación con la historia. ${ }^{13}$ Este último tema, pone en discusión la relativización y la escatología de algunas de las formas tomadas por la Iglesia. Sin embargo, algunos otros estudios, exploran la religiosidad como una característica social, imbricada en las relaciones humanas que intentan dar respuesta a las dudas planteadas por la propia condición humana. ${ }^{14}$

\footnotetext{
${ }^{11}$ Alberto Ramírez, "Eucaristía y sacerdocio", Cuestiones Teológicas Vol. 4 No. (2018): 62-77. Alberto Ramírez, "Fundamentos doctrinales para una teología sobre la acción del laico" Cuestiones Teológicas Vol. 10 No.26 (2018): 24-35.

12 Jean Paul Sarrazin, “¿Guiados por Dios o por Sí Mismos? Estudio comparativo entre adeptos a las espiritualidades alternativas y adeptos a las iglesias evangélicas”, Cuestiones Teológicas Vol. 44, No. 102 (2017): 373-396.

${ }^{13}$ Adolfo Galeano-Atehortúa, "Una eclesiología histórica-escatológica para la postmodernidad. el cambio de paradigma dentro de la orientación postmoderna hacia la historia y la hermenéutica", Cuestiones Teológicas Vol. 44 No.102 (2017): 397-421.

${ }^{14}$ Carlos Arboleda Mora, "Factores sociológicos de la religiosidad colombiana", Cuestiones Teológicas Vol. 10 No. 26 (2018): 36-49. Jhon Pérez Vargas y María Cabrera Vásquez. “Desafíos pedagógicos a la formación en la etapa de noviciado de comunidades religiosas". Cuestiones Teológicas Vol. 46, No. 106 (2019): 272-294.
} 


\section{Referencias}

Arboleda Mora, Carlos. "Factores sociológicos de la religiosidad colombiana", Cuestiones Teológicas Vol. 10 No. 26 (2018): 36-49.

Arango Restrepo, Pablo. "Estatuto del embrión humano." Escritos Vol. 24 No.53 (2016): 307-318. http://dx.doi.org/10.18566/escr.v24n53.a04 Berryman, Phillip. Teología de la liberación: Ios hechos esenciales en torno al movimiento revolucionario en América Latina y otros lugares (Siglo XXI, 1989).

Dulles, Avery. A History of Apologetics (Ignatius Press, 2005).

Dussel, Enrique. Teología de la Liberación: Un panorama de su desarrollo (Potrerrillo, 1995).

Díez Fischer, Francisco. "La hermenéutica de Gadamer como escucha tras las huellas ¿Una hermenéutica de lo inaparente?". Escritos Vol. 26, No. 56 (2018): 21-61. http://dx.doi.org/10.18566/escr.v26n56.a02

Ellacuría, Ignacio. "La teología de la liberación frente al cambio sociohistórico de América Latina." Revista latinoamericana de teología vol. 4, no. 12, p. 241-263. (1987).

Galeano-Atehortúa, Adolfo. "Una eclesiología histórica-escatológica para la postmodernidad. el cambio de paradigma dentro de la orientación postmoderna hacia la historia y la hermenéutica", Cuestiones

Teológicas Vol. 44 No.102 (2017): 397-421.

http://dx.doi.org/10.18566/cueteo.v44n102.a08

Gómez Díaz, Jairo. Adriana Alejandra Hoyos Camacho, Rosana Elena Navarro Sánchez, et al., "El sentido teológico de una espiritualidad en camino la espiritualidad de la liberación entre Puebla y Santo Domingo", Cuestiones Teológicas Vol. 43, No. 99 (2016): 149-174.

http://dx.doi.org/10.18566/cueteo.v43n99.a07

Gutiérrez, Gustavo, y Lucas F. Mateo Seco. Teología de la liberación (Lima: CEP, 1971).

Illanes, José Luis y Josep-Ignasi Saranyana, Historia de la Teología, Biblioteca de Autores Cristianos 2002.

Lois, Julio. Teología de la liberación: opción por los pobres. Vol. 1. (IEPALA Editorial, 1986). 
McNally, Terrence J. What Every Catholic Should Know about Mary (Xlibris Corporation, 2009)

Pérez Prieto, Victorino. "Los orígenes de la teología de la liberación en Colombia Richard Shaull, Camilo Torres, Rafael Ávila, "Golconda", sacerdotes para América Latina, cristianos por el socialismo y comunidades eclesiales de base", Cuestiones Teológicas Vol. 43, No. 99 (2016): 73-108. https://dx.doi.org/10.18566/cueteo.v43n99.a04

Pérez Vargas, Jhon y María Cabrera Vásquez. "Desafíos pedagógicos a la formación en la etapa de noviciado de comunidades religiosas". Cuestiones Teológicas Vol. 46, No. 106 (2019): 272-294 http://doi.org/10.18566/cueteo.v46n106.a04

Pérez Vargas, Jhon y María Cabrera Vásquez. "Desafíos pedagógicos a la formación en la etapa de noviciado de comunidades religiosas".

Cuestiones Teológicas Vol. 46, No. 106 (2019): 272-294

http://doi.org/10.18566/cueteo.v46n106.a04

Ramírez, Alberto. "Eucaristía y sacerdocio", Cuestiones Teológicas Vol. 4 No. (2018): 62-77.

Ramirez, Alberto. "Fundamentos doctrinales para una teología sobre la acción del laico”, Cuestiones Teológicas Vol. 10, Núm 26 (1983).

Ramírez, Alberto. "Fundamentos doctrinales para una teología sobre la acción del laico" Cuestiones Teológicas Vol. 10 No.26 (2018): 24-35.

Ramírez, Alberto. "La teología del laicado desde el Concilio Vaticano II hasta el sínodo mundial actual" Cuestiones Teológicas Vol. 14 No.39 (2019): 47-64.

Rowland, Christopher ed, La teología de la liberación. Vol. 7. (Ediciones AKAL, 2000).

Sanhueza Vidal, Kreti Soledad. "Jesucristo, prototipo de justicia y martirio, a favor de los pobres y marginados", Cuestiones Teológicas Vol. 43, No. 99 (2016): 175-197. http://dx.doi.org/10.18566/cueteo.v43n99.a08

Sarrazin, Jean Paul. "Budismo Universal, Budismo Individual. Análisis Del Interés Por La Espiritualidad Oriental En Occidente". Escritos Vol. 25, N. 54 (2017): 59-81. ISSN: 2390-0032

Sarrazin, Jean Paul. “¿Guiados por Dios o por Sí Mismos? Estudio comparativo entre adeptos a las espiritualidades alternativas y adeptos a 
las iglesias evangélicas", Cuestiones Teológicas Vol. 44, No. 102 (2017): 373-396. http://dx.doi.org/10.18566/cueteo.v44n102.a07

Sayés, José Antonio. Escatología (Madrid: Ediciones Palabrea, 2006). Sobrino, Jon. "La centralidad del "reino de Dios" en la teología de la liberación." Revista latinoamericana de teología vol. 3, no. 9, p. 247281. (1986).

Tahar Chaouch, Malik. "La teología de la liberación en América Latina: una relectura sociológica." Revista mexicana de sociología 69.3 (2007): 427-456.

Toro Jaramillo, Iván Darío. "La bibliometría y las publicaciones en Teología”, Cuestiones Teológicas Vol. 44 No.102 (2018): 229-239. http://dx.doi.org/10.18566/cueteo.v44n102.a01

Turriago Rojas, Daniel. "La actitud de la Iglesia Católica colombiana durante las hegemonías liberal y conservadora de 1930 a 1953", Cuestiones Teológicas Vol. 44, No. 101 (2017): 67-94.

http://dx.doi.org/10.18566/cueteo.v44n101.a04 